\title{
Molecular detection of vector-borne pathogens in blood and splenic samples from dogs with splenic disease
}

\author{
Rebeca Movilla', Laura Altet ${ }^{2}$, Lorena Serrano², María-Dolores Tabar ${ }^{3}$ and Xavier Roura ${ }^{1 *}$
}

\begin{abstract}
Background: The spleen is a highly perfused organ involved in the immunological control and elimination of vector-borne pathogens (VBP), which could have a fundamental role in the pathogenesis of splenic disease. This study aimed to evaluate certain VBP in samples from dogs with splenic lesions.

Methods: Seventy-seven EDTA-blood and 64 splenic tissue samples were collected from 78 dogs with splenic disease in a Mediterranean area. Babesia spp., Bartonella spp., Ehrlichia/Anaplasma spp., Hepatozoon canis, Leishmania infantum, hemotropic Mycoplasma spp. and Rickettsia spp. were targeted using PCR assays. Sixty EDTA-blood samples from dogs without evidence of splenic lesions were included as a control group.

Results: More than half (51.56\%) of the biopsies (33/64) were consistent with benign lesions and $48.43 \%$ (31/64) with malignancy, mostly hemangiosarcoma (25/31). PCR yielded positive results in 13 dogs with spleen alterations (16.67\%), for Babesia canis $(n=3)$, Babesia gibsoni $(n=2)$, hemotropic Mycoplasma spp. $(n=2)$, Rickettsia massiliae $(n=1)$ and "Babesia vulpes" $(n=1)$, in blood; and for B. canis, B. gibsoni, Ehrlichia canis and L. infantum ( $n=1$ each), in spleen. Two control dogs (3.3\%) were positive for B. gibsoni and H. canis ( $n=1$ each). Benign lesions were detected in the $61.54 \%$ of infected dogs (8/13); the remaining $38.46 \%$ were diagnosed with malignancies (5/13). Infection was significantly associated to the presence of splenic disease $(P=0.013)$. There was no difference in the prevalence of infection between dogs with benign and malignant splenic lesions $(P=0.69)$; however $B$. canis was more prevalent in dogs with hemangiosarcoma $(P=0.006)$.

Conclusions: VBP infection could be involved in the pathogenesis of splenic disease. The immunological role of the spleen could predispose to alterations of this organ in infected dogs. Interestingly, all dogs with $B$. canis infection were diagnosed with hemangiosarcoma in the present survey. As previously reported, results support that VBP diagnosis could be improved by analysis of samples from different tissues. The sample size included here warrants further investigation.
\end{abstract}

Keywords: Canine, Vector-borne disease, Spleen, Polymerase chain reaction, Hemangiosarcoma, Babesia canis

\section{Background}

Vector-borne pathogens (VBP) are arthropod-transmitted agents, mainly parasites and bacteria, which cause a significant impact on the health of dogs. In addition to their veterinary importance, dogs can act as reservoirs for VBP of major zoonotic concern [1]. The risks of canine vectorborne diseases (CVBD) infection and the severity of clinical

\footnotetext{
*Correspondence: xavier.roura@uab.cat

${ }^{1}$ Hospital Clínic Veterinari, Universitat Autònoma de Barcelona, Carrer de L'Hospital s/n, 08193 Bellaterra, Cerdanyola del Vallès, Barcelona, Spain Full list of author information is available at the end of the article
}

signs are a consequence of a complex interrelationship between the infectious agent, the arthropod vector and immune response of the dog [2]. Substantial evidence supports that the spleen plays a key role in the immunopathology of CVBD [3]. However, the development of splenic disease in itself has also been anecdotally associated with the presence of VBP infections in dogs $[4,5]$.

The spleen is a secondary lymphoid organ specialized in filtering blood-borne pathogens and antigens by both innate and adaptive immune response. The splenic red pulp contains macrophages that trap and remove 
damaged red blood cells. The blood flow pattern and a subset of specialized macrophages ensure that the antigen-presenting cells capture and deliver these bloodborne antigens to the $\mathrm{B}$ cells in the marginal zone. Afterwards, antibody-producing cells migrate from the primary follicles in the white pulp, colonize the marginal zone and move into the red pulp, where antibody production occurs before blood returning to the circulation [6]. Further characterization of the immunological phenomena, developed in the spleen of VBP-infected dogs and other mammals, remains subject of continuous investigation. The acute splenic response of calves to Babesia bovis was remarkably similar to that reported in a mouse model of malarial infection indicating that dynamic changes in the distribution of splenic cells is common in the acute response to the hemoparasitic infection [7]. It was shown that the spleen is able to retain Bartonella spp. using an experimental mouse model, although the mechanisms of retention have still to be elucidated [8]. During the acute phase of experimentally induced canine monocytic ehrlichiosis, high levels of tumor necrosis factor (TNF)- $\alpha$ expression were found in splenocytes, CD8+ cells were decreased while CD3+ cells were increased, which could have occurred as an immunologic modulation in the spleen contributing to the pathogenesis. Furthermore, immunohistochemistry revealed a higher number of immunoglobulin (Ig) $\mathrm{M}$ and IgG immunolabeled cells responsible, at least in part, for the morphological changes observed in this organ $[9,10]$.

Several reports have been focused on describing the cellular immunophenotypic profile in the splenic compartment and the co-expression of Th1 pro-inflammatory cytokines [such as interferon (IFN)- $\gamma$, interleukin (IL)-12 and TNF- $\alpha$ ] and Th2 anti-inflammatory/regulatory cytokines [such as tumor growth factor (TGF)- $\beta$, IL-4 and IL10], throughout the course of natural and experimental visceral leishmaniosis $[11,12]$. The large number of cells (lymphocytes) undergoing apoptosis in the spleen of dogs with visceral leishmaniosis was correlated with the parasite load, which suggested that this process could be a contributing factor for the survival of the protozoon in this organ [13]. Of note, splenectomy was considered one of the main clinical outbreaks of hemotropic Mycoplasma spp. infection in splenectomized dogs [14]. Theileria equi was found in the spleen of asymptomatic horses that did not show parasitemia, which suggested that this might be an important tissue supporting the persistence of the parasite in the host [15].

On the other hand, VBP infection can induce changes in the architecture of the spleen. Conditions such as babesiosis that increase the size of this organ elevate the risk of parenchymal disruption [16]. Bartonella spp. infection has been associated to the presence of granulomatous splenic lesions, abscess, and vasoproliferative tumors, such as hemangiopericytoma and hemangioendothelioma in dog and human patients, respectively [17-19]. Molecular confirmation supported higher prevalence for Bartonella spp. compared to Babesia spp. and hemotropic Mycoplasma spp. in dogs with fibrohistiocytic nodules (FHN) and hemangiosarcoma (HSA) in the spleen [4]. Mechanistic evidence as to how these bacteria contribute to the development of vasoproliferative lesions has been provided [5]. Additionally, splenic vasculitis, thrombosis and infarction, were recently documented in a febrile dog diagnosed with Bartonella henselae [20]. Moreover, a comparative experimental infection study in dogs infected with Ehrlichia spp. and Anaplasma spp. described infiltration of perivascular mononuclear cells into the spleen, more severe for ehrlichial infections [21]. Leishmania infantum and Hepatozoon canis were identified in the spleen of dogs with splenitis [22]; and progressive spleen architecture breakage in visceral leishmaniosis was characterized by disorganization of the white pulp, associated with a more frequent and intense plasma cell accumulation in this organ, mostly in dogs with high parasite density [23].

The present study aimed to evaluate the prevalence of certain VBP commonly found in the Mediterranean area, such as Babesia spp., Bartonella spp., Ehrlichia/Anaplasma spp., H. canis, L. infantum, hemotropic Mycoplasma spp. and Rickettsia spp., in dogs with splenic disease and to investigate potential associations of these pathogens with the development of splenic lesions.

\section{Methods}

\section{Sample collection}

Fresh splenic tissue and/or ethylene diamine tetraacetic acid (EDTA)-blood samples from dogs undergoing splenectomy in two Referral Veterinary Hospitals located in a Mediterranean area, were collected and stored immediately after surgery $\left(-20{ }^{\circ} \mathrm{C}\right)$, between January 2010 and June 2016. Diagnosis of splenic disease was based on a combination of clinical signs, laboratory testing, diagnostic imaging assessment, findings on surgical exploration of the abdominal cavity, and cytological and/or histopathological evaluation of the spleen. For 17 cases in which fresh splenic tissue samples were not collected, available paraffin-embedded surgical biopsy samples were retrieved from pathology archive storage facilities, using the Pathology Data Base. Although not at the same time, splenic tissue samples were processed and paraffin-embedded with the same equipment and techniques. Board-certified veterinary pathologists performed the histopathological evaluation of the splenic tissue samples.

Control EDTA-blood samples were prospectively collected and stored $\left(-20{ }^{\circ} \mathrm{C}\right)$ from dogs with or without clinical signs attending the hospitals for unrelated reasons during the same period, but whose spleens were 
deemed within normal limits on imaging assessment (ultrasound and/or computed tomography). All splenic tissue and EDTA-blood samples were identified and processed for polymerase chain reaction (PCR).

Signalment was recorded and medical information was reviewed for every dog. Verbal owner consent was received for all dogs prior to their enrolment in the study. This study was carried out in accordance with the International Guiding Principles for Biomedical Research Involving Animals, issued by the Council for the International Organizations of Medical Sciences.

\section{PCR testing}

DNA from splenic tissue was extracted using the Purelink ${ }^{\circ}$ Genomic DNA Kit following manufacturer instructions (Thermo Fisher Scientific, Waltham, MA, USA). DNA was extracted from $400 \mu \mathrm{l}$ of whole blood as previously described [24]. Collected samples, previously defined as specific pathogen-free (SPF) by PCR, were used as an extraction negative control in each extraction batch. Samples were tested in an operator blind manner. Babesia spp., Bartonella spp., Ehrlichia/Anaplasma spp., H. canis, hemotropic Mycoplasma spp. and Rickettsia spp. were targeted using specific PCR assays (Table 1). Real time PCR was carried out in a total volume of $20 \mu \mathrm{l}$ containing SYBR $^{\circ}$ Select master mix (Thermo Fisher Scientific), specific primer (see Table 1 for sequence and concentration) and $4 \mu \mathrm{l}$ of $1 / 5$ diluted DNA. The thermal cycling profile was $50{ }^{\circ} \mathrm{C}$ for 2 min and $95{ }^{\circ} \mathrm{C}$ for 10 min followed by 40 cycles at $95{ }^{\circ} \mathrm{C}$ for $15 \mathrm{~s}$ and $60^{\circ} \mathrm{C}$ for $1 \mathrm{~min}$ and a dissociation curve added at the end of the run. Water was used as PCR negative control and commercial DNAs as positive PCR control. In all cases in which splenic tissue and EDTA-blood samples were PCR-positive, direct DNA sequencing was performed to characterize pathogens at the species level. Sequencing was done by the BigDye Terminator v3.1 Cycle Sequencing Kit (Thermo Fisher Scientific) following the manufacturer instructions and with the same primers used in the PCR and sequences compared with the GenBank database (https://blast.ncbi.nlm.nih.gov/Blast.cgi). The eukaryotic $18 \mathrm{~S}$ ribosomal ribonucleic acid (rRNA) (Thermo Fisher Scientific) was used as an endogenous control to ensure proper DNA extraction. Quantitative L. infantum PCR was performed as described by Francino and collaborators [24].

\section{Statistical analysis}

Statistical analysis was performed using SPSS 20.0 software. Values for the prevalence of Babesia spp., Bartonella spp., Ehrlichia/Anaplasma spp., H. canis, L. infantum, hemotropic Mycoplasma spp. and Rickettsia spp. were established. Chi-square and Fisher's exact test were used to compare proportions of positivity. The level of statistical significance considered was $P<0.05$.

\section{Results}

A total of 138 dogs were enrolled in this study. Additional file 1: Table S1 shows in detail the signalment, samples collected, histopathological diagnosis and PCR results.

Seventy-eight dogs were included in the group with spleen alterations, 40 female (51.94\%) and 37 male (48.05\%). Twenty-seven different breeds were represented including crossbreed dogs $(n=15)$, German Shepherd $(n=13)$, Boxer $(n=6)$, English Cocker Spaniel $(n=5)$, Golden Retriever $(n=4)$, Beagle $(n=3)$, French Bulldog $(n=3)$, Great Dane $(n=3)$, Labrador Retriever $(n=3)$, and others $(n=22)$. Age of dogs in this group ranged from 3 to 16 years, with a mean age of 9 years. Signalment was partially unknown for four dogs. The control group included 60 dogs, 35 female $(58.3 \%)$ and 25 male (41.7\%). Twenty-four different breeds were represented including: crossbreed dogs $(n=14)$, Yorkshire Terrier $(n=9)$, Golden Retriever $(n=5)$, Boxer $(n=3)$, German Shepherd $(n=3)$, Miniature Schnauzer $(n=3)$, and others $(n=23)$. Age of dogs in this group ranged from 1 to 16 years, with a mean age of 8.3 years. Histopathology of the spleen was performed in 64 out of 78 dogs with spleen alterations. Benign lesions were

Table 1 PCR targets and primers used in this study for detection of Babesia spp., Bartonella spp., Ehrlichia/Anaplasma spp., H. canis, hemotropic Mycoplasma spp. and Rickettsia spp.

\begin{tabular}{|c|c|c|c|c|c|}
\hline Species & $\begin{array}{l}\text { Target } \\
\text { gene }\end{array}$ & Forward primer $\left(5^{\prime}-3^{\prime}\right)$ & Reverse primer (5'-3') & $\begin{array}{l}\text { Final primer } \\
\text { concentration }(\mu \mathrm{M})\end{array}$ & Reference \\
\hline Babesia spp. & $18 \mathrm{~S}$ rRNA & GACGATCAGATACCGTCGTAGTCC & CAGAACCCAAAGACTITGATTTCTCTC & 0.3 & {$[62]$} \\
\hline Bartonella spp. & ITS1 & AGATGATGATCCCAAGCCTTCTG & CCTCCGACCTCACGCTTATCA & 0.3 & $\begin{array}{l}\text { Modified from } \\
{[63,64]}\end{array}$ \\
\hline $\begin{array}{l}\text { Ehrlichia spp.; } \\
\text { Anaplasma spp. }\end{array}$ & $16 \mathrm{~S}$ rRNA & GCAAGCYTAACACATGCAAGTCG & GGATTATACAGTATTACCCAYCATTTCTARTG & 0.5 & {$[65,66]$} \\
\hline H. canis & $18 \mathrm{~S}$ rRNA & CTTACCGTGGCAGTGACGGT & ATTGTTATTCTTGTTACTACСTСTCTCAAAC & 0.3 & {$[66]$} \\
\hline $\begin{array}{l}\text { Hemotropic } \\
\text { Mycoplasma spp. }\end{array}$ & $16 \mathrm{~S}$ rRNA & ATGTTGCTTAATTCGATAATACACGAAA & ACRGGATTACTAGTGATTCCAACTTCAA & $0.3 / 0.5$ & {$[65]$} \\
\hline Rickettsia spp. & ITS2 & GCTCGATTGRTITACTITGCTGTGAG & CATGCTATAACCACCAAGCTAGCAATAC & $0.5 / 0.3$ & {$[62]$} \\
\hline
\end{tabular}


observed in the $51.56 \%(33 / 64)$. The most common were lymphoid nodular hyperplasia $(\mathrm{LNH})(n=10)$, congestion $(n=9)$, necrosis $(n=7)$, hematoma $(n=5)$, extramedullary hematopoiesis $(n=4)$, and hemosiderosis $(n=3)$. Some dogs were histopathologically diagnosed with more than one benign splenic lesion. Malignant lesions were observed in the remaining $48.43 \%$ (31/64). The most common was HSA $(n=25)$, followed by carcinoma $(n=2)$, lymphoma $(n=2)$, FHN $(n=1)$, and undifferentiated sarcoma $(n=1)$. Nine out of the 78 dogs with spleen alterations were diagnosed with splenic torsion, two with splenic rupture due to a blunt abdominal trauma, and three were euthanized. The owners refused further investigation in these 14 cases, so histopathological assessment of the spleen could not be performed.

PCR was positive for 15 out of 138 dogs included (10.9\%). For dogs with spleen alterations, 13 out of 78 (16.67\%) were PCR-positive for at least one VBP when either splenic tissue $(n=4)$ or blood $(n=9)$ was tested. On the other hand, only 2 out of 60 control dogs (3.3\%) were found PCR-positive for VBP. In the 13 positive dogs, agreement was not found for PCR outcome between splenic tissue and EDTA-blood samples obtained from the same dog. PCR results, type of biological samples analyzed in positive cases, and histopathological diagnosis of the spleen when it was available, are shown in Table 2. Statistical analysis revealed that VBP infection was significantly associated to the presence of splenic disease $\left(\chi^{2}=6.223, d f=1, P<0.05\right)$. Relationship between VBP infection and the character of the splenic lesions was clinically presumed $\left(\chi^{2}=0.161, d f=1, P>\right.$
0.05). Indeed, all dogs infected with $B$. canis were diagnosed with HSA $\left(\chi^{2}=7.473, d f=1, P<0.05\right)$.

\section{Discussion}

In the study presented here, PCR detected a higher prevalence of VBP in dogs with splenic alterations (16.67\%) as compared with dogs without evidence of splenic changes (3.3\%), which supports a potential relationship between the pathogenesis of CVBD and splenic diseases.

To the best of our knowledge, the literature contains only one report by Varanat and collaborators on molecular prevalence of certain VBP in dogs with specific splenic conditions [4]. In the latter study, Bartonella spp. DNA was more frequently detected in FHN (29.7\%), HSA (26\%) and LNH (10\%) compared to Babesia spp. (2.7, 2.0 and 2.0\%, respectively) and hemotropic Mycoplasma spp. (0, 6 and 0\%, respectively), while all of the paraffin-embedded splenic tissues from dogs with histologically unremarkable spleens were PCR negative [4]. Differences observed between dogs with splenic disease and control dogs in the study of Vranat et al. [4] are in agreement with results obtained here. In contrast, specific prevalence of infection with Bartonella spp., Babesia spp. and Mycoplasma spp. disagree greatly. Differences in epidemiological conditions and populations tested could explain such discrepancy. However, the absence of Bartonella spp. DNA in dogs with splenic disease, mainly vasoproliferative tumor-like lesions, was unexpected in our investigation. Molecular evidence supports that four species of Bartonella, alone or in coinfection, could potentially induce vasoproliferative

Table 2 Relationship between histopathological examination of spleen tissue samples and vector-borne pathogens detected

\begin{tabular}{llll}
\hline Dog & PCR result & Sample & Hystopathology \\
\hline S1 & Babesia canis & Frozen spleen & HSA \\
S2 & Babesia canis & EDTA-blood & HSA \\
S3 & Babesia canis & EDTA-blood & HSA \\
S4 & Babesia canis & EDTA-blood & EH, hemosiderosis, LNH \\
S5 & Babesia gibsoni & Paraffin-fixed spleen & Congestion, hematoma \\
S6 & Babesia gibsoni & EDTA-blood & Congestion \\
S7 & Babesia gibsoni & EDTA-blood & na \\
C1 & Babesia gibsoni & EDTA-blood & na (splenic torsion) \\
S8 & "Babesia vulpes" & EDTA-blood & Congestion, hematoma \\
S9 & Ehrlichia canis & Frozen spleen & na \\
C2 & Hepatozoon canis & EDTA-blood & EH, myeloid metaplasia \\
S10 & Leishmania infantum & Frozen spleen & Congestion, EH, hemosiderosis \\
S11 & "Candidatus Mycoplasma hemovis" & EDTA-blood & Carcinoma \\
S12 & Mycoplasma ovis & EDTA-blood & LNH \\
S13 & Rickettsia massilliae & EDTA-blood & \\
\hline
\end{tabular}

Abbreviations: S, dogs with spleen alterations, C, control dogs, EH extramedullary hematopoiesis, HSA hemangiosarcoma, LNH lymphoid nodular hyperplasia, na not available 
lesions [5]. Bartonella infection induces overlapping mechanisms in the development of vasoproliferative tumors, such as direct mitogenic effect on endothelial cells, inhibition of endothelial cell apoptosis and activation of hypoxia inducible factor-I $\alpha$, resulting in increased expression of the vascular endothelial growth factor [25-28]. In Spain, serological evidence of Bartonella spp. exposure and molecular detection of the genera have been reported in dogs [29-31]. However, diagnosis of bartonellosis represents a challenge [31] and could be the main cause of the difference in the prevalence of Bartonella spp. between the study by Varanat et al. [4] and the present study. The use of a combined approach of serology, pre-enrichment culture of Bartonella spp. in Bartonella alpha proteobacteria growth medium (BAPGM) and PCR may enhance the diagnostic confirmation of bartonellosis in blood or tissue samples of naturally infected dogs [20,31, 32].

In contrast, Babesia spp. showed the highest prevalence in the present survey (6.52\%) with nine out of 138 dogs infected. Similar rate of molecular detection for Babesia spp. in EDTA-blood samples (5\%) was reported for dogs from the same area presenting for compatible clinical signs and/ or criteria with ehrlichiosis during 2011 [33]. The spleen protects against Babesia spp. by ingestion and clearance of infected red blood cells [34]. Infected erythrocytes could alter spleen histopathology, cause cell cycle alteration (G0/ G1, S, and G2/M phases) and induce oxidative stress in splenic tissue, as indicated by decreased glutathione, catalase and superoxide dismutase levels [35]. Damaged red blood cells, iron, free radicals and other reactive oxygen species from macrophage activation produce DNA damage in endothelial cells [36]. Moreover, once activated, macrophages are the main source of growth factors and cytokines (such as TNF- $\alpha$, IL-12 and IFN- $\gamma$ ), which profoundly affect endothelial, epithelial and mesenchymal cells in the local microenvironment [37-39]. It is now becoming clear that the tumor microenvironment, which is largely coordinated by inflammatory cells, is an essential contributor in the neoplastic process, promoting proliferation, survival and migration [39]. These phenomena coupled together could provide the events necessary for the induction of HSA [36]. In the present study, PCR testing identified four dogs infected with $B$. canis and, interestingly, all of them were diagnosed with HSA. On the other hand, a potential causative role in the development of splenitis has been attributed to the presence of mesenchymal neoplastic diseases [22]. As previously described, HSA could predispose to alter the splenic vasculature, thrombosis, and abnormal blood flows, possibly favoring bacterial engraftment [40].

Hemotropic Mycoplasma ovis was PCR-detected in one out of two dogs diagnosed with splenic carcinoma. Many studies have indicated that persistent exposure to Mycoplasma spp. is closely associated with oncogenic transformation in human cancers and have found that the Mycoplasma p37 protein alone is sufficient to increase the invasiveness and metastases of cancer cells [41-44]. Mycoplasma spp. DNA was successfully extracted and amplified from multiple forms of human carcinoma [44-46]. Experimental data indicated that some Mycoplasma spp. cause chromosomal changes and cell transformations in vitro through progressive chromosomal loss and translocations. However, the relationship between Mycoplasma spp. infection and cancer progression is yet to be disclosed [45].

Evidence supports that infiltration and activation of inflammatory cells confer favorable conditions for the progression of cancer, inducing angiogenesis, tumor growth and invasion [46]. To elucidate whether VBP induce such infiltration and activation of inflammatory cells in the spleen or alternatively are attracted to preexisting neoplastic splenic inflammatory lesions, thereby explaining DNA detection of VBP in these dogs, warrants further investigation.

Remaining VBP infected dogs showed benign splenic diseases or were control dogs. Four of these were infected with B. gibsoni. In contrast to reported data, breed predisposition was not observed for this infection [47]. Histopathology was not available for the only "B. vulpes"-infected dog that was diagnosed with splenic torsion associated with gastric-dilation volvulus (GDV). Evidence supports that "B. vulpes" is genetically related to B. gibsoni [48]. Trotta et al. [49] described a B. gibsoni-infected dog with suspected splenic torsion. In such case, histopathological evaluation of the spleen revealed white and red pulp hyperplasia, associated with a diffuse granulocytic infiltrate, hemorrhages and massive necrosis with vascular thrombosis, suggestive of splenic infarct [49]. In addition, a dog with splenic torsion and PCR positive for L. infantum was also reported [22]. In this case, the authors considered that both conditions might have triggered splenitis because of altered vascularity and blood supply or activation of the reticuloendothelial system. The etiology of primary splenic torsion (PST) and the association between PST and GDV is unclear, with anecdotal evidence suggesting that dogs with history of PST have an increased risk of developing GDV [50]. Based on the former information, we hypothesize that in the dog of the present study splenic changes associated with VBP infection could have induced PST, and potentially secondary GDV.

Anaplasma spp. was not detected in any dog. Furthermore, in the present study, prevalence of Ehrlichia canis, L. infantum, $H$. canis and Rickettsia massilliae was lower than expected given previous reports conducted in the same area $[29,30]$. These findings combined, suggest that these pathogens may be underestimated in the current study. As previously described, several factors could 
prompt failure to reach PCR diagnosis, such as small quantity of tissue placed in paraffin blocks from markedly enlarged spleens and the limited quantity of extracted DNA (host and pathogen) that can be incorporated into each PCR reaction, storage conditions and varying periods of formalin fixation that could induce DNA degradation, and/or decreased microorganism load in systemic circulation, possibly associated with the use of specific treatment before obtaining the samples $[4,31,51]$.

Serological and PCR assays used in parallel could have maximized CVBD diagnosis [52]. However, in agreement with previous publications, the results obtained in blood and tissue samples from dogs with spleen alterations support that sampling from different tissues improved detection of VBP infection [53-56]. The tropism of certain VBP, such as $L$. infantum caused by lymphoid organs makes them important for detecting this protozoan [56]. It has been shown that positivity increases with disease progression and dogs without clinical signs present lower tissue parasitism, while dogs with clinical signs have high parasite loads in tissues such as the spleen [57]. Moreover, parasites do not distribute themselves evenly in all tissues [58]. Several parameters should be considered in choosing the sample to be used with special care to avoid excessive invasiveness and potential risks for the dog, such as pain, infection or hemorrhage [59].

None of the PCR-positive dogs in the present study showed VBP infection on histopathology of the spleen. As previously described, it is possible that some splenic macrophages had phagocytosed DNA fragments, but intact microorganisms were not detectable, so the amplification methods used with PCR allowed positive results with very small amounts of DNA, while this was not achievable by means of histopathology [22].

There were some limitations in the present study, which have still to be mentioned. Due to the partially retrospective nature of this research and the fact that dogs attended at different institutions, information gathered from available medical records was sometimes incomplete. Furthermore, obtaining optimal age and sex-matched groups was not entirely possible because splenectomy is performed only when there is overt evidence of splenic alterations and splenic biopsies are infrequently obtained. In addition, it is not possible to rule out differences in the processing of the paraffin-embedded tissue samples, retrieved from the pathology archive storage facilities, which were obtained before the frozen-samples collection period. Moreover, control dogs without evidence of splenic alterations were selected based on diagnostic imaging assessment; although ultrasonography and/or radiological splenic changes have shown a good correlation with other laboratory examinations in CVBD, histopathology could have been useful to further confirm the absence of splenic disease in such cases $[60,61]$. In addition, samples were stored and retrieved from archives, so prior contamination could not be completely excluded.

\section{Conclusions}

This study provides additional evidence that CVBD could be involved in the pathogenesis of splenic alterations. The high prevalence of $B$. canis infection in dogs with splenic HSA suggests a potential role for this pathogen in the development of vasoproliferative tumors. Furthermore, based on the results obtained here, the presence of splenic disease should prompt further investigation for detection of VBP infection, mainly in endemic areas. Detection of VBP infection is improved by sampling of different tissues.

\section{Additional file}

Additional file 1: Table S1. Details for signalment, collected samples, histopathological diagnosis and PCR results for dogs included in this study. (XLSX $54 \mathrm{~kb}$ )

\section{Abbreviations}

BAPGM: Bartonella alpha proteobacteria growth medium; C: control dog; CVBD: canine vector-borne disease; DNA: deoxyribonucleic acid;

EDTA: ethylene diamine tetraacetic acid; EH: extramedullary hematopoiesis; FHN: fibrohistiocytic nodules; GDV: gastric dilation volvulus; HSA: hemangiosarcoma; IBD: inflammatory bowel disease; Ig: immunoglobulin; IL: interleukin; ITS: internal transcribed spacer; LNH: Iymphoid nodular hyperplasia; PST: primary splenic torsion; rRNA: ribosomal ribonucleic acid; S: splenectomized dog; SPF: specific pathogen free; TGF: tumor growth factor; TNF: tumor necrosis factor; VBP: vector-borne pathogens

\section{Acknowledgements}

Bayer Animal Health has sponsored this manuscript in the framework of the 12th CVBD World Forum Symposium. Authors are indebted to the veterinarians participating in this study, the owners of dogs included and the dogs themselves. The authors also thank two anonymous reviewers.

Funding

Not applicable.

Availability of data and material

The dataset supporting the conclusions of this article is included within the article and its Additional file 1.

\section{Authors' contributions}

XR designed the present survey. MDT, RM and XR collected samples and recorded the dog data. $L A$ and $L S$ performed PCR assays. RM performed the statistical analysis of data. LA and RM constructed the tables. LA and RM drafted the first version of the manuscript. MDT, RM and XR reviewed and finalized the manuscript. All authors read and approved the final manuscript.

\section{Competing interests}

The authors declare that they have no competing interests.

\section{Consent for publication}

Not applicable.

\section{Ethics approval and consent to participate}

Collected data and samples used in this study were obtained from the diagnostic protocol and/or treatment of dogs included, under consent of the owners and in accordance with the International Guiding Principles for Biomedical Research Involving Animals, issued by the Council for the International Organizations of Medical Sciences. 


\section{Publisher's Note}

Springer Nature remains neutral with regard to jurisdictional claims in published maps and institutional affiliations.

\begin{abstract}
Author details
'Hospital Clínic Veterinari, Universitat Autònoma de Barcelona, Carrer de L’Hospital s/n, 08193 Bellaterra, Cerdanyola del Vallès, Barcelona, Spain. ${ }^{2}$ Vetgenomics, Edifici Eureka, Parc de Recerca de la Universitat Autònoma de Barcelona, 08193 Bellaterra, Cerdanyola del Vallès, Barcelona, Spain. ${ }^{3}$ Hospital Veterinario San Vicente, Calle del Veterinario Manuel Isidro Rodríguez García №17, 03690 San Vicente del Raspeig, Alicante, Spain.
\end{abstract}

Received: 18 January 2017 Accepted: 2 March 2017 Published online: 13 March 2017

\section{References}

1. Otranto D, Dantas-Torres F, Breitschwerdt EB. Managing canine vector-borne diseases of zoonotic concern: part one. Trends Parasitol. 2009;25:157-63.

2. Day MJ. The immunopathology of canine vector-borne diseases. Parasit Vectors. 2011;13:48.

3. Bronte $\mathrm{V}$, Pittet MJ. The spleen in local and systemic regulation of immunity Immunity. 2013:39:806-18.

4. Varanat M, Maggi RG, Linder KE, Breitschwerdt EB. Molecular prevalence of Bartonella, Babesia, and hemotropic Mycoplasma sp. in dogs with splenic disease. J Vet Intern Med. 2011;25:1284-91.

5. Beerlage C, Varanat M, Linder K, Maggi RG, Cooley J, Kempf VAJ, et al. Bartonella vinsonii subsp. berkhoffii and Bartonella henselae as potential causes of proliferative vascular diseases in animals. Med Microbiol Immunol. 2012;201:319-26.

6. Tizard IR. Organs of the immune system. In: Tizard IR, editor. Veterinary Immunology. 9th ed. St. Louis, MO: Elsevier Saunders; 2013. p. 124-6.

7. Schneider DA, Yan H, Bastos RG, Johnson WC, Gavin PR, Allen AJ, et al. Dynamics of bovine spleen cell populations during the acute response to Babesia bovis infection: an immunohistological study. Paras Immunol. 2011:33:34-44.

8. Deng HK, Le Rhun D, Lecuelle B, Le Naour E, Vayssier-Taussat M. Role of the spleen in Bartonella spp. infection. FEMS Immunol Med Microbiol. 2012;64: 143-5.

9. Faria JLM, Demarchi T, Franchi C, Vargas-Hernandez G, André MR, Biscola WA, et al. Ehrlichia canis (Jabotical strain) induces the expression of TNF-a in leukocytes and splenocytes of experimentally infected dogs. Rev Bras Parasitol. 2011;20:71-4

10. Botelho M, Zacarias R, Padilha L, Alessi AC, Tinucci M. Experimental acute canine monocytic ehrlichiosis: clinicopathological and immunopathological findings. Vet Parasitol. 2004;119:73-86.

11. Barbosa A, Teixeira-Carvalho A, Giunchetti RC, Roat BM, Coura-Vital W, Nicolato $R$ de $C$, et al. Cellular immunophenotypic profile in the splenic compartment during canine visceral leishmaniasis. Vet Immunol Immunopathol. 2014;157:190-6

12. Cavalcanti AS, Ribeiro-Alves M, Pereira L de OR, Mestre GL, Ferreira ABR, Morgado FN, et al. Parasite load induces progressive spleen architecture breakage and impairs cytokine mRNA expression in Leishmania infantumnaturally infected dogs. PLoS One. 2015;10, e0123009.

13. Moreira PR, Franciscato DA, Rossit SM, Munari DP, Vasconcelos $\mathrm{R}$ de $\mathrm{O}$. Influence of apoptosis on liver and spleen resistance in dogs with visceral leishmaniosis. Rev Bras Parasitol Vet. 2016;25:342-7.

14. Kemming G, Messick JB, Mueller W, Enders G, Meisner F, Muenzing S, et al Can we continue research in splenectomized dogs? Mycoplasma haemocanis: old problem-new insight. Eur Surg Res. 2004;36:198-205.

15. Ribeiro IB, Câmara AC, Bittencourt MV, Marçola TG, Paludo GR, Soto-Blanco B. Detection of Theileria equi in spleen and blood of asymptomatic piroplasm carrier horses. Acta Parasitol. 2013;58:218-22.

16. Leinwand JC, Arroyo JP, Solomon D, Kaplan L. Babesia microti infection presenting as acute splenic laceration. Surg Inf. 2013;14:412-4.

17. Saunders GK, Monroe WE. Systemic granulomatous disease and sialometaplasia in a dog with Bartonella infection. Vet Pathol. 2006;43:391-2.

18. Anyfantakis D, Kastanakis M, Papadomichelakis A, Petrakis G, Bobolakis E. Cat-scratch disease presenting as a solitary splenic abscess in an immunocompetent adult: case report and literature review. Infez Med. 2013:2:130-3.
19. Breitschwerdt EB, Maggi RG, Varanat M, Linder KE, Weinberg G. Isolation of Bartonella vinsonii subsp. berkhoffi genotype II from a boy with Epitheliod Hemangioendothelioma and a dog with hemangiopericytoma. J Clin Microb. 2009:47:1957-60.

20. Friedenberg SG, Balakrishnan N, Guillaumin J, Cooper ES, Lewis K, Russell DS, et al. Splenic vasculitis, thrombosis, and infarction in a febrile dog infected with Bartonella henselae. J Vet Emerg Crit Care (San Antonio). 2015;25:789-94.

21. Morgado FN, Cavalcanti AD, Miranda LH, O'Dwyer LH, Silva MR, Menezes RC, et al. Hepatozoon canis and Leishmania spp. coinfection in dogs diagnosed with visceral leishmaniasis. Rev Bras Parasitol Vet. 2016;25:450-8.

22. Ferri F, Zini E, Auriemma E, Castagnaro M, Coppola LM, Peano A, et al. Splenitis in 33 dogs. Vet Pathol. 2017;54:147-54.

23. Silva-O'Hare J, de Oliveira IS, Klevorn T, Almeida VA, Oliveira GG, Atta AM, et al. Disruption of splenic lymphoid tissue and plasmacytosis in canine visceral leishmaniasis: changes in homing and survival plasma cells. PLoS One. 2016;11:e0156733.

24. Francino O, Altet $L$, Sanchez-Robert E, Roura X. Advantages of real-time PCR assay for diagnosis and monitoring of canine leishmaniosis. Vet Parasitol. 2006;137:214-21.

25. Conley T, Slater L, Hamilton K. Rochalimaea species stimulate human endothelial cell proliferation and migration in vitro. J Lab Clin Med. 1994; 124:521-8.

26. Kirby JE, Nekorchuk DM. Bartonella-associated endothelial proliferation depends on inhibition of apoptosis. Proc Natl Acad Sci USA. 2002;99:4656-61.

27. Kempf VAJ, Lebiedziejewski M, Alitalo K, Wälzlein J, Ehehalt U, Fiebig J, et al. Activation of hypoxia inducible factor-1 in bacillary angiomatosis: evidence for a role of HIF-1 in bacterial infections. Circulation. 2005;111:1052-62.

28. Kempf VAJ, Volkmann B, Schaller M, Sander CA, Alitalo K, Riess T, et al. Evidence of a leading role for VEGF in Bartonella henselae-induced endotelial cell proliferations. Cell Microbiol. 2001;3:623-32.

29. Roura X, Breitschwerdt EB, Lloret A, Ferrer L, Hegarty B. Serological evidence of exposure to Rickettsia, Bartonella, and Ehrlichia species in healthy or Leishmania infected dogs from Barcelona, Spain. Intern J Appl Res Vet Med. 2005:3:129-37.

30. Tabar MD, Francino O, Altet L, Sanchez A, Ferrer L, Roura X. PCR survey of vector-borne pathogens in dogs living in and around Barcelona, an area endemic for leishmaniosis. Vet Rec. 2009;164:112-6.

31. Tabar MD, Maggi RG, Altet L, Villafranca M, Francino O, Roura X. Gammopathy in a Spanish dog infected with Bartonella henselae. J Small Anim Pract. 2011;52:209-12.

32. Duncan AW, Maggi RG, Breitschwerdt EB. A combined approach for the enhanced detection and isolation of Bartonella species in dog blood samples: pre-enrichment liquid culture followed by PCR and subculture onto agar plates. J Microbiol Methods. 2007;69:273-81.

33. René-Martellet M, Lebert I, Chêne J, Massot R, Leon M, Leal A, et al. Diagnosis and incidence risk of clinical canine monocytic ehrlichiosis under field conditions in southern Europe. Parasit Vectors. 2015;8:3.

34. Vannier EG. Babesiosis. Infect Dis Clin North Am. 2015;29:357-70.

35. Dkhil MA, Al-Quraishy S, Al-Khalifa MS. The effect of Babesia divergens infection on the spleen of Mongolian gerbils. Biomed Res Int. 2014:2014:483854

36. Corthals SM, Kamendulis LM, Klauning JE. Mechanisms of 2-Butoxyethanolinduced hemangiosarcomas. Toxicol Sci. 2006:92:378-86.

37. Vannier E, Krause PJ. Human babesiosis. New Eng J Med. 2012;366:2397-407.

38. Krause PJ, Daily J, Telford SR, Vannier E, Lantos P, Spielman A. Shared features in the pathobiology of babesiosis and malaria. Trends Parasitol. 2007;23:605-10

39. Coussens LM, Werb Z. Inflammation and cancer. Nature. 2002;420:860-7.

40. Laurenson MP, Hopper K, Herrera MA, Johnson EG. Concurrent diseases and conditions in dogs with splenic vein thrombosis. J Vet Intern Med. 2010;24: 1298-304.

41. Pehlivan M, Pehlivan S, Onay H, Koyuncuoglu M, Kirkali Z. Can mycoplasma mediated oncogenesis be responsible for formation of conventional renal cell carcinoma? Urology. 2005;65:411-4.

42. Ketcham CM, Anai S, Reutzel R, Sheng S, Schuster SM, Brenes RB, et al. P37 induces tumor invasiveness. Mol Cancer Ther. 2005:4:1031-8.

43. Urbanek C, Goodison S, Chang M, Porvasnik S, Sakamoto N, Li CZ, et al. Detection of antibodies directed at $M$. hyorhinis p37 in the serum of men with newly diagnosed prostate cancer. BMC Cancer. 2011;11:233.

44. Huang S, Li JY, Wu J, Meng L, Shou CC. Mycoplasma infections and different human carcinomas. World J Gastroenterol. 2001;7:266-9. 
45. Choi HS, Lee HM, Kim WT, Kim MK, Chang HJ, Lee HR. Detection of Mycoplasma infection in circulating tumor cells in patients with hepatocellular carcinoma. Biochem Biophys Res Commun. 2014;446:620-5.

46. Ono M. Molecular links between tumor angiogenesis and inflammation: inflammatory stimuli of macrophages and cancer cells as targets for therapeutic strategy. Cancer Sci. 2008;99:1501-6.

47. Birkenheuer AJ, Correa MT, Levy MG, Breitschwerdt EB. Geographic distribution of babesiosis among dogs in the United States and association with dog bites: 150 cases (2000-2003). J Am Vet Med Assoc. 2005;227:942-7.

48. Camacho AT. Piroplasma infection in dogs in northern Spain. Vet Paras. 2006:138:97-102

49. Trotta M, Carli E, Novari G, Furlanello T, Solano-Gallego L. Clinicopathological findings, molecular detection and characterization of Babesia gibsoni infection in a sick dog from Italy. Vet Parasitol. 2009;12:318-22.

50. DeGroot W, Giuffrida MA, Rubin J, Runge JJ, Zide A, Mayhew PD, et al. Primary splenic torsion in dogs: 102 cases (1992-2014). J Am Vet Med Assoc. 2016;248:661-8.

51. Breitschwerdt EB, Kordick DL. Bartonella infection in animals: carriership, reservoir potential, pathogenicity, and zoonotic potential for human infection. Clin Microb Rev. 2000;13:428-38.

52. Maggi RG, Birkenheuer AJ, Hegarty BC, Bradley JM, Levy MG, Breitschwerdt EB. Comparison of serological and molecular panels for diagnosis of vectorborne diseases in dogs. Parasit Vectors. 2014;7:127.

53. Barrouin-Melo SM, Larangeira DF, Trigo J, Palis PH, Conrado WL, Pontes-deCarvalho L. Comparison between splenic and lymph node aspirations as sampling methods for the parasitological detection of Leishmania chagasi infection in dogs. Mem Inst Oswaldo Cruz, Rio de Janeiro. 2004;99:195-7.

54. Eddlestone SM, Gaunt SD, Neer TM, Boudreaux CM, Gill A, Haschke E, et al. PCR detection of Anaplasma platys in blood and tissue of dogs during acute phase experimental infection. Exp Parasitol. 2007;115:205-10.

55. Faria LM, Dagnone AS, Munhoz TD, João CF, Pereira WAB, Machado RZ, et al. Ehrlichia canis morulae and DNA detection in whole blood and spleen aspiration samples. Rev Bras Parasitol Vet. 2010;19:98-102.

56. Reis LE, Coura-Vital W, Roatt BM, Bouillet LÉ, Ker HG, de Brito RC F, et al. Molecular diagnosis of canine visceral leishmaniasis: comparative study of three methods using skin and spleen from dogs with natural Leishmania infantum infection. Vet Parasitol. 2013:197:498-503.

57. Reis AB, Martins-Filho OA, Teixera-Carvalho A, Giunchetti RC, Carneiro CM, Mayrink W. Systemic and compartmentalized immune response in canine visceral leishmaniasis. Vet Immunol Immunopathol. 2009;12:87-95.

58. Maia C, Campino L. Methods for diagnosis of canine leishmaniasis and immune response to infection. Vet Parasitol. 2008;158:274-87.

59. Ramos RA, Ramos CA, Santos EM, de Araújo FR, de Carvalho GA, Faustino MA, et al. Quantification of Leishmania infantum DNA in the bone marrow lymph node and spleen of dogs. Rev Bras Parasitol Vet. 2013;22:346-50.

60. Sarma K, Mondal DB, Saravanan M. Ultrasonographic changes in dogs naturally infected with vector borne intracellular diseases. J Parasit Dis. 2014; 40:248-51.

61. van der Veer-Meerkerk M, van Zaanen HC. Visceral involvement in an immunocompetent male: a rare presentation of cat scratch disease. Neth J Med. 2008;66:160-2.

62. Pennisi MG, Persichetti MF, Serrano L, Altet L, Reale S, Gulotta L, et al. Ticks and associated pathogens collected from cats in Sicily and Calabria (Italy). Parasit Vectors. 2015;8:512

63. Maggi RG, Harms CA, Hohn AA, Pabst DA, McLellan WA, Walton WJ, et al. Bartonella henselae in porpoise blood. Emerg Infect Dis. 2005;11:1894-8.

64. Gil H, García-Esteban C, Barandika JF, Peig J, Toledo A, Escudero R, et al. Variability of Bartonella genotypes among small mammals in Spain. Appl Environ Microbiol. 2010;76:8062-70.

65. Cabello J, Altet L, Napolitano C, Sastre N, Hidalgo E, Dávila JA, et al. Survey of infectious agents in the endangered Darwin's fox (Lycalopex fulvipes): high prevalence and diversity of hemotrophic mycoplasmas. Vet Microbiol. 2013:167:448-54.

66. Vilhena H, Martinez-Díaz VL, Cardoso L, Vieira L, Altet L, Francino O, et al. Feline vector-borne pathogens in the north and centre of Portugal. Parasit Vectors. 2013:6:99.

\section{Submit your next manuscript to BioMed Central and we will help you at every step:}

- We accept pre-submission inquiries

- Our selector tool helps you to find the most relevant journal

- We provide round the clock customer support

- Convenient online submission

- Thorough peer review

- Inclusion in PubMed and all major indexing services

- Maximum visibility for your research

Submit your manuscript at www.biomedcentral.com/submit

) Biomed Central 